\title{
El testimonio en Latinoamérica: usos y destinos
}

\author{
NATALIA DE MARINIS Y MORNA MACLEOD
}

Testimony in Latin America:

Its Usages and Destinies

NATALIA DE MARINIS

Centro de Investigaciones y Estudios Superiores en Antropología Social-Golfo,

Xalapa, Veracruz, México nataliademarinis@ciesas.edu.mx

MORNA MACLEOD

Universidad Autónoma del Estado de Morelos,

Cuautla, Morelos, México morna.macleod@uaem.mx

Desacatos 62,

enero-abril 2020, pp. 8-17 a organización temática de este número de Desacatos responde a una serie de preguntas acerca de los usos y destinos del testimonio en escenarios de conflicto, posconflicto, construcción de memoria y búsqueda de justicia en Latinoamérica. Más allá de la enorme variedad de usos del testimonio y sus destinos literarios, biográficos e históricos, entre otros, nuestro interés está en los escenarios nacionales e internacionales de justicia formal y alternativa, y en la dimensión política central de la construcción de la denuncia y la memoria colectiva en contextos de violencia y transiciones democráticas. En esta entrega confluimos académicas socialmente comprometidas, que hemos trabajado con testimonios vinculados a víctimas y movimientos por los derechos humanos en varios países latinoamericanos - Argentina, Chile, Guatemala y México- Nuestras preocupaciones giran en torno a los efectos, circulaciones y recepción de los testimonios entre las propias víctimas, testigos y audiencias más amplias, para entender y demostrar cómo tejen solidaridades y luchas por la memoria y la verdad en el contexto de entramados y continuum de violencias, y también la manera en la que los perpetradores de crímenes de lesa humanidad utilizan estas reivindicaciones de verdad, memoria y justicia en contextos neoconservadores.

Estas preocupaciones parten de una diversidad de enfoques disciplinarios —antropológicos, sociológicos, psicológicos-, la intervención terapéutica con víctimas de represión política y la experiencia como testigos expertas en espacios judiciales. No sólo coincidimos en la importancia de la construcción de conocimiento en torno al testimonio, sino también en su articulación con acciones políticas y de intervención en escenas diversas. Concordamos con John Beverly (2008) en que los tipos de testimonio producidos en y sobre Latinoamérica son una contribución importante tanto para el público en general como para la academia pues desestabilizan las fronteras dentro y entre la literatura, las ciencias sociales, la psicología y la antropología. 


\section{El testimonio, la memoria colectiva y su carácter polisémico}

El siglo XX se ha considerado el escenario del testimonio. Sobre todo desde la Primera Guerra Mundial, la humanidad ha sido testigo de la emergencia de "masas de testimonios", aunque no fue sino hasta mediados de siglo cuando el Holocausto se convirtió en el acontecimiento histórico que originaría su circulación masiva (Wieviorka, 2006). Su diseminación tenía que ver con el deber de memoria que el horror vivido en los campos de concentración había instalado. Al final de su libro Los hundidos y los salvados, Primo Levi planteó que hablar con los jóvenes era un deber porque podía suceder de nuevo:

Ha ocurrido contra las previsiones; ha ocurrido en Europa; increíblemente, ha ocurrido que un pueblo entero civilizado, apenas salido del ferviente florecimiento cultural de Weimar, siguiese a un histrión cuya figura hoy mueve a risa; y, sin embargo, Adolfo Hitler ha sido obedecido y alabado hasta su catástrofe. Ha sucedido y, por consiguiente, puede volver a suceder: esto es la esencia de lo que tenemos que decir (1989: 173).

La búsqueda de no repetición marcó buena parte de los testimonios de masacres y represión política a partir de entonces. La emergencia del testimonio y la memoria no fue, sin embargo, automática. La guerra fue capaz de avergonzar, silenciar y horrorizar al punto de lo indecible; generó miedo a no ser escuchado, a no ser creído, hasta el grado de impedir testimoniar. Para Levi, los verdaderos testigos habían sido aniquilados, no sólo con su muerte, sino con la muerte de su capacidad humana. Los sobrevivientes, los que no habían tocado fondo, fueron los que pudieron escribir la historia de los Lager.

Walter Benjamin (2001), en su ensayo "El narrador", advertía el mismo horror y silenciamiento entre los soldados de la Primera Guerra Mundial.
Su experiencia, como suceso comprensible, habría sido aniquilada por la imposibilidad de ser narrada (Sarlo, 2006). Sin embargo, esta condición no suprimió el testimonio. En los retornos a la democracia en Sudamérica, en los auges de masacres y conflictos centroamericanos y europeos - en particular, en relación con el Holocausto-, las víctimas tomaron la palabra. Los testimonios se convirtieron en pruebas de lo que se había pretendido ocultar con el asesinato, la desaparición y el horror enmudecedor. Fueron los vehículos de la verdad de las atrocidades, los mecanismos de investigación de hechos y la materia prima en los espacios de justicia oficial y justicia alternativa, como los tribunales permanentes y las comisiones de verdad. ${ }^{1}$

Ser escuchados y creídos fue una de las características más importantes de estos escenarios, que de alguna manera revertían el silenciamiento al que Levi tanto temía. El testimonio se planteó en un carácter relacional que suponía una paradoja. La imposibilidad de testimoniar del verdadero testigo, del desaparecido o de quien había tocado fondo y estaba paralizado por el sufrimiento y la incomprensión (Levi, 1989) se tornó el centro de la posibilidad misma de testimoniar, al tiempo que el testimonio adquiría un carácter colectivo, en tanto esa incapacidad del testigo se desenvolvía e involucraba a otros. En este carácter relacional del testimonio se inscribe no sólo su función jurídica, sino también histórica y de memoria colectiva (Gutiérrez y Noailles, 2014).

En Los trabajos de la memoria, Elizabeth Jelin (2002) utiliza el concepto de huella testimonial para situar la característica relacional y colectiva del testimonio y sus efectos en la construcción de la memoria. La mirada relacional muestra que los testimonios

Desde la década de 1980 se conformaron cerca de 40 comisiones de verdad en el mundo, promovidas por organismos internacionales o por los propios países. Sus resultados han sido diversos, como se verá en esta introducción. 
implican a testigos, que además se convierten en actores centrales de su transmisión y circulación en escenarios más amplios. Como acontecimiento, la huella requiere un conjunto de narraciones que adquiere relevancia en colectivo, pues importa más lo que la narración individual dice del acontecimiento que la veracidad de la narración misma (Ricoeur, 1999). Si bien la experiencia es individual y única, los testimonios se entregan...

en respuesta a preguntas y expectativas motivadas por preocupaciones políticas e ideológicas. Consecuentemente, a pesar de su unicidad, los testimonios vienen a participar en una memoria colectiva -o memorias colectivas- que varían en su forma, función y en los objetivos implícitos o explícitos que se fijaron para sí mismos (Wieviorka, 2006: vii).

Los testimonios representan y se expresan en marcos culturales y sociales más amplios. Maurice Halbwachs (2004), quien propuso la noción de memoria colectiva en la década de 1920, plantea que la memoria es colectiva en tanto los recuerdos se evocan, reconocen y localizan en marcos sociales específicos. Estos marcos, que también son espaciales y temporales, permiten generar una continuidad de los recuerdos que no es simplemente una sumatoria. La representación de esta continuidad como movimiento surge gracias a la existencia de un medio social que hace posible su conexión - Halbwachs utiliza la metáfora del río como marco y el tronco como acontecimiento-.

En este aspecto, la memoria colectiva es fundamental para fortalecer el sentido de pertenencia de grupos y comunidades porque vincula la identidad y la historia compartida (Pollak, 2006; Rappaport, 2000). La relación entre pasado y presente cobra un significado particular en las situaciones postraumáticas porque los actos de rememorar y olvidar reactivan experiencias que ayudan a comprender y situar el presente en un continuum histórico para la reconstrucción del sí mismo individual y colectivo (Pollak, 2006).

Sin embargo, como se ha analizado, en contextos de posconflicto estas memorias irrumpen en arenas controversiales. Steve Stern (2000) explora la diversidad de memorias colectivas emblemáticas en disputa y cómo las que se constituyen en hegemónicas varían de un periodo a otro. En el caso de Chile, por ejemplo, durante buena parte de la dictadura militar la memoria del golpe de Estado como "salvación" fue la hegemónica. ${ }^{2}$ Durante la transición democrática cedió ante la memoria como "prueba", definida por un proceso de lucha por el respeto a los derechos humanos. También están presentes la memoria como "ruptura lacerante no resuelta", que se reduce a los familiares, ex presos políticos, etc., que no logran superar el trauma del golpe y la represión; y hay otra memoria, como "caja cerrada", en la que se opta por olvidar y no querer asumir los conflictos de un país profundamente dividido.

Lo crucial de los testimonios son los acontecimientos colectivos que evocan y que abren la posibilidad de reconstrucción de la comunidad política fragmentada por el terror y el silenciamiento:

La memoria-olvido, la conmemoración y el recuerdo se tornan cruciales cuando se vinculan a experiencias traumáticas colectivas de represión y aniquilación, cuando se trata de profundas catástrofes sociales y situaciones de sufrimiento colectivo. Son estas memorias y olvidos los que cobran una significación especial en términos de los dilemas de la pertenencia a la comunidad política. Las exclusiones, los silencios y las inclusiones a las

De acuerdo con esta memoria, el general Pinochet habría salvado al pueblo chileno del supuesto caos del gobierno socialista de Salvador Allende. 
que se refieren hacen a la re-construcción de comunidades que fueron fuertemente fracturadas $y$ fragmentadas en las dictaduras y los terrorismos de Estado de la región (Jelin, 2002: 98).

El testimonio tiene un papel central en los espacios de justicia, ya sea para la recolección de hechos y pruebas, el establecimiento de responsabilidad o para la paz y el perdón, pero también cumple un papel fundamental en la construcción de la memoria y la reconstrucción de individuos y sociedades tanto durante como después de los eventos traumáticos. Esta mirada amplía el testimonio a otras acciones perfomativas transmisoras de conocimientos y memorias que no están ancladas necesariamente en la oralidad (Beverley, 2008; Jelin, 2002; Taylor, 2003).

En Latinoamérica, los testimonios tienen un largo antecedente que incluye la literatura de los pueblos originarios (Stephen, 2017), los textos de la Conquista y la colonización, documentos que se centran en la vida de luchadores sociales, y relatos sobre luchas militares y sociopolíticas. George Yúdice (2002) recalca de manera acertada las raíces de la teología de la liberación y la concientización de Freire en gran parte los testimonios latinoamericanos. Michal Givoni (2011) relaciona la "canonización" del testimonio como lenguaje subversivo de los grupos oprimidos y subalternos con la denuncia de atrocidades cometidas por el Estado. Una veta importante de los testimonios proviene del triunfo de la Revolución cubana, en 1959, y la fundación de la Casa de las Américas un año después, que inauguró un premio para la categoría "Testimonio" en 1970 (Forné, 2014). Se trata de testimonios con la extensión de una novela, que se centran en personas y luchas revolucionarias. La premiación de dos escritores uruguayos es ilustrativa. La primera en recibir el premio fue la periodista María Esther Gilio, con su libro La guerrilla tupamara, en 1970, y luego Eduardo Galeano, en 1979, por Días y noches de amor y de guerra (Forné, 2014: 221).
Los testimonios se expresan en novelas (Alcoba, 2008; Abad, 2014), crónicas (Poniatowska, 1971; García, 1990) y biografías (Colom, 1998; Friedman, 2008), como "Si me permiten hablar...". Testimonio de Domitila, una mujer de las minas de Bolivia (Viezzer, 1977) y Me llamo Rigoberta Menchú y así me nació la conciencia (Burgos, 1983). Aunque comparten ciertas características con la historia oral, las biografías y las autobiografías, y se ha cuestionado si deben o no considerarse literatura (Franco, 2002), existe un acuerdo acerca de que los testimonios no necesariamente involucran la grabación, preservación e interpretación del pasado (Stephen, 2017).

Estas distinciones se tornan imprecisas en la vasta literatura sobre el testimonio. Como plantea René Jara, "más que una interpretación de la realidad esta imagen es, ella misma, una huella de lo real, de esa historia que, en cuanto tal, es inexpresable. La imagen inscrita en el testimonio es un vestigio material del sujeto" (citado en Acedo, 2017: 45). Nos detendremos en esta definición, el testimonio como huella, para analizar su función en la reconstrucción de la memoria, la justicia y la verdad en la historia reciente.

\section{Los testimonios del pasado reciente}

Las dictaduras en el Cono Sur y las guerras centroamericanas en el contexto de represión política y masacres implicaron prácticas de violencia poco conocidas en nuestros países. Las nuevas formas de terror y genocidio a las que se enfrentaron amplios sectores de la sociedad mediante la tortura, los asesinatos y la desaparición de personas buscaban imponer el miedo, el terror y el silencio a la sociedad entera. La clandestinidad y el silencio alrededor de las masacres tenían como fin, en muchos casos, no dejar evidencia alguna, destruir las pruebas. El horor supuso también la prohibición de la palabra y la desinformación permanente mediante propaganda antisubversiva. Todos estos mecanismos de control 


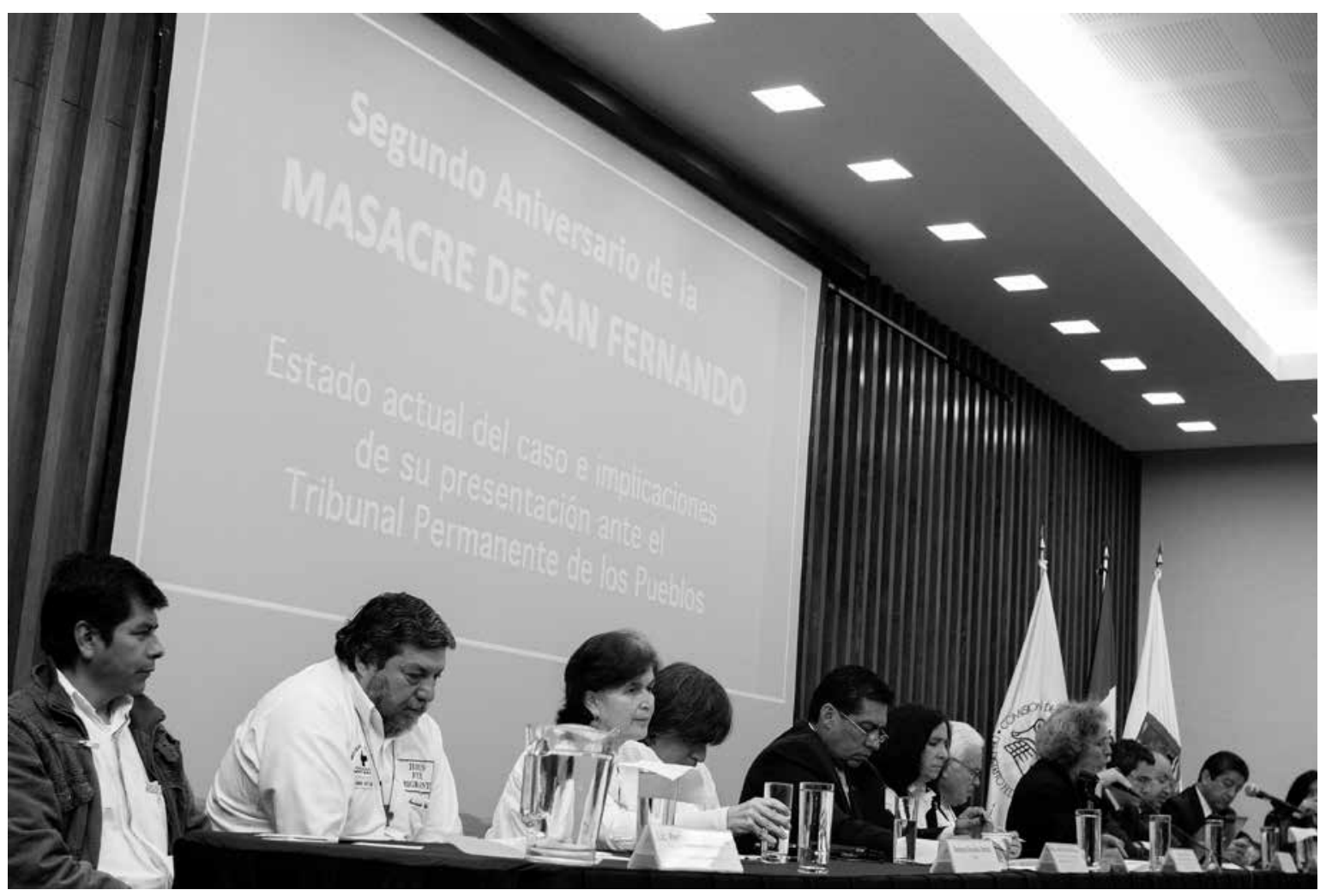

Prometeo Lucero - Tribunal Permanente de los Pueblos, Comisión de Derechos Humanos del Distrito Federal. Ciudad de México, 21 de agosto de 2012.

convirtieron los testimonios de víctimas y testigos en engranajes centrales para la memoria, la verdad y la justicia en los contextos de transición, y en actos de denuncia y resistencia durante las masacres (Macleod, en este número).

La presencia de víctimas y testigos que rompieron el silencio para dar lugar a la voz y narrar la experiencia se concretó en dos campos centrales e interrelacionados: el jurídico, en el que el testimonio y la documentación de los casos por organizaciones de derechos humanos fueron el eje en la condena a perpetradores de la violencia, y en un sentido más amplio, una dimensión fundamental de la vida democrática; y el campo político y de la memoria, en el que se instalaron acciones de memoria colectiva surgidas de sectores subalternos contra el olvido y para la no repetición. Los sitios de conmemoración se convirtieron también en una forma de narrar y grabar la experiencia (Vecchioli, 2012).

Elizabeth Lira, académica y psicóloga por los derechos humanos en Chile, pionera en el tratamiento terapéutico del testimonio, plantea que, ante el silencio y la falta de palabras como síntomas iniciales de los sobrevivientes de la tortura y la represión política, el testimonio cumplía una función de justicia y reparación en un sentido personal y emocional: "hablar y decir permitía ordenar en parte las dimensiones caóticas y fragmentadas del recuerdo" (2007: 11). Los testimonios formaron parte de múltiples espacios, desde los de demandas colectivas a partir de la repetición de la narración, hasta los psicoterapéuticos, que se convirtieron en evidencias para la Comisión Nacional de Prisión Política y Tortura en Chile (Lira, en este número). 
Para Pilar Calveiro, el material testimonial es fundamental en la articulación del relato histórico resistente:

El testimonio expone junto a otros una verdad, "su”" verdad, que reclama una cierta escucha y validación social para ser parte de "la" verdad socialmente construida. Por ejemplo, algunos sobrevivientes relatan que sólo cuando su testimonio fue considerado como prueba para la condena a los comandantes, en el Juicio a las Juntas, sentían que lo que les había pasado y lo que ya habían contado muchas veces era realmente "verdadero" (2006: 79).

Los testimonios fueron piezas esenciales para empezar procesos de investigación de hechos en litigios de justicia penal — como los juicios por delitos de lesa humanidad en Argentina o el juicio por genocidio a Efraín Ríos Montt en Guatemala- o crear alternativas, como las comisiones de verdad y tribunales de conciencia. ${ }^{3}$ Desde la década de 1980 , los propios países o instancias internacionales construyeron estos espacios de justicia alternativa con fines muy variados: la reconciliación, la paz, la preparación de procesos penales para los responsables, la recolección de datos, evitar la desaparición de pruebas, la reparación, entre otros. No cabe duda de que en la actualidad éstos y otros escenarios de justicia y memoria han abierto importantes posibilidades para la visibilización de violencias y memorias soterradas. Sin embargo, han surgido voces críticas acerca de los tratamientos y condiciones en las que se instalaron estos procesos, que en algunos casos generaron ocultamiento de agravios y exclusión de amplios sectores de la sociedad, con el riesgo siempre latente de provocar mayor impunidad.

Para Alejandro Castillejo (2009), quien analiza la comisión de verdad en Sudáfrica después del apartheid, la restricción de las voces y de dimensiones centrales del apartheid definieron la legitimidad o el silenciamiento de ciertos testimonios y agravios en la comisión de la verdad. Menciona la ironía del reconocimiento, que se funda en la creación de toda una "industria del testimonio y el trauma" y cuyo efecto adverso es el silenciamiento. Kimberly Theidon (2009) trató algo similar respecto a lo que denominó la violencia de la memoria en el caso de la comisión de verdad en Perú, en la que la imposición del testimonio a poblaciones rurales sucedió en un contexto de extrema marginalidad e impunidad, y generó silencios por falta de protección a testigos y dependencia de recursos materiales, y circunscribió las narrativas del dolor de las mujeres a un lenguaje de humillación que difícilmente podría detonar procesos de sanación y justicia. ${ }^{4}$ Para otros autores, los marcos que instalaron estas comisiones hicieron que los sobrevivientes claudicaran en la posibilidad de reivindicar una agencia social antisistémica, pues se redujo el espacio y sólo se les permitía ser víctimas (Rodríguez, 2011; Givoni, 2011; Castillejo, 2007).

En contextos de impunidad continua, la construcción de la verdad enfrenta retos y riesgos mayores. Los mecanismos institucionales de verdad, sin un proceso de justicia y castigo a los responsables, pueden erosionar la confianza y fragmentar aún más los tejidos comunitarios y las comunidades políticas de por sí dañados por décadas de violencia. En contextos en los que la violencia histórica y generalizada no permite definir límites precisos o referentes claros entre víctimas y victimarios, en los que se asiste a una debilidad de las instituciones de justicia ordinarias, los procesos alternativos de verdad y justicia se tornan aún más complejos. La definición de la víctima y el daño podría dar sentidos muy disímiles a la base del conflicto, y por lo tanto, a la de

Los tribunales éticos o de conciencia son iniciativas ciudadanas performativas y cuasi legales en contextos de impunidad, que emulan los juicios e ilustran cómo debería funcionar la justicia.

$4 \quad$ Para el caso de Guatemala, véase Crosby y Lykes (2011).
} 
la responsabilidad. Si hablamos de violencia colonial o violencia estructural, ¿quiénes serían los responsables principales? ¿Quiénes serían víctimas y quiénes victimarios en estos escenarios desterritorializados de la violencia? ¿Dónde se ubica el dolor y el trauma? ¿Quién es el objeto legítimo de la reparación? ¿Cuáles son las condiciones mínimas que deben garantizarse para que los testimonios de víctimas no sean usados para prolongar y profundizar la impunidad? Estas interrogantes y otras muchas guían la construcción de este número de Desacatos.

Nombrar la violencia se está convirtiendo cada vez más en un mecanismo de visibilización de agravios que contribuye a la reparación y sanación de poblaciones enteras, pero no se habla de la misma guerra en todos los casos, la noción de víctima abarca un periodo histórico y relaciones mucho más amplios. La victimización de los pueblos indígenas en Perú, Guatemala o en la experiencia reciente en Colombia - con la instalación de la comisión de la verdad luego de los Acuerdos de Paz de 2017 y de instituciones como el Proceso de Justicia y Paz y el Grupo de Memoria Histórica- plantea una historicidad que supera la posibilidad de las propias comisiones, pero que también las silencian o corren el riesgo de hacerlo (Castillejo, 2007; Jimeno, Varela y Castillo, 2018).

Los testimonios se han convertido en una forma de documentación importante para la antropología, aún en contextos en los que no se han establecido mecanismos de justicia transicional. Sólo por mencionar algunas, destacamos la experiencia de Myriam Jimeno y su equipo, con desplazados forzados luego de la masacre del Naya (Jimeno, Varela y Castillo, 2015); la de Lynn Stephen (2016), con manifestantes de la Asamblea Popular de los Pueblos de Oaxaca en 2006; los testimonios expertos en procesos judiciales para garantizar los derechos a solicitantes de refugio en Estados Unidos (De Marinis, en este volumen; Stephen, 2017; Campbell, Slack y Diedrich, 2017), y los peritajes de violaciones graves a los derechos humanos, como el de Rosalva Aída Hernández Castillo y Héctor Ortiz Elizondo (2012) para la Corte Interamericana de Derechos Humanos, en el caso de dos mujeres indígenas de Guerrero, víctimas de violencia sexual por parte del ejército. Éstos y otros materiales testimoniales de la antropología colaborativa han sido fuente de inspiración para reflexiones previas, publicadas en el libro Resisting Violence: Emotional Communities in Latin America (Macleod y De Marinis, 2018).

También nos apoyamos en una literatura emergente acerca de los testimonios de victimarios o de sus familiares (Vela, 2014; Robledo, 2017; Vecchioli y Fioravanti, en este número), que podrían abonar no sólo a la dificultad de llevar a cabo procesos de justicia, sino también a promover la justificación de masacres y violencia. Estos testimonios irrumpen en un contexto de retroceso democrático en varios países de Latinoamérica y hacen eco a deseos no previstos de amplios sectores de la sociedad. Se filtran y retoman los discursos de décadas de luchas por los derechos humanos y requieren una atención especial.

\section{Las contribuciones de este número}

Los usos, expresiones y transformaciones del testimonio han sido vistos a través de múltiples lentes. En lo más íntimo, el testimonio es una posibilidad de sanación cuando se comparte el dolor con otros y se conectan sucesos y detalles, es una herramienta terapéutica. En el aspecto relacional, la circulación de testimonios más allá de la víctima crea lazos de solidaridad y compromiso con quienes son testigos de los sucesos, y los efectos políticos del testimonio se expanden. Por sus implicaciones jurídicas en espacios institucionales específicos, el testimonio oral es un elemento fundamental para reconstruir sucesos y agravios, pero también es objeto de tratamientos cuestionables, tanto de objetividad como 
de garantía de impunidad. A partir de sus implicaciones políticas, permite construir la memoria, la reparación y la búsqueda de la no repetición.

En este número de Desacatos reflexionamos de manera crítica sobre sus usos políticos y jurídicos para visibilizar y construir agravios en contextos de represión política, conflictos armados y nuevas expresiones de la violencia y la guerra, con límites territoriales y temporales porosos. A partir de experiencias que involucran testimonios de víctimas y perpetradores en espacios no institucionales e institucionales, como las cortes, analizamos sus usos y efectos para la construcción de verdad y justicia a corto, mediano y largo plazo, en arenas complejas, caracterizadas por los giros conservadores actuales en nuestro continente.

El artículo de Elizabeth Lira se adentra en los sentidos del testimonio de víctimas de tortura durante la dictadura militar en Chile (1973-1990), con base en sus efectos psicoterapéuticos y colectivos en la construcción de la memoria, y como parte del trabajo que encaró la Comisión Nacional de Prisión Política y Tortura en Chile. El potencial de los testimonios, en términos de reparación y construcción de la verdad, descubre la dimensión colectiva y política aún en aquellos escenarios en apariencia íntimos. Elizabeth Lira fue parte de estos procesos y también una referencia en el entendimiento de la función terapéutica y política de los testimonios durante la dictadura chilena.

Morna Macleod analiza los testimonios de hombres y mujeres mayas sobre la violencia durante el conflicto armado en Guatemala, en el Tribunal Permanente de los Pueblos y otras fuentes, como la revista Polémica. Más que rememoraciones del pasado en contextos de transición política, estos testimonios tuvieron la característica de construirse en tiempo real durante las masacres, para crear una arena internacional de condena y denuncia. Macleod retoma los testimonios y explora sus ediciones posteriores y las entrevistas actuales, las características, potencialidades y constreñimientos de esos testimonios, que muestran tanto la libertad de nombrar el derecho a la rebelión como los agravios silenciados.

Virginia Vecchioli y Eduardo Fioravanti analizan un aspecto poco tratado en relación con el uso y destino de los testimonios de integrantes de las Fuerzas Armadas y de Seguridad, juzgados por delitos de lesa humanidad en Argentina, y personas allegadas. Estudian decenas de testimonios publicados de manera periódica en la prensa nacional Argentina, país modelo en cuanto a las demandas por derechos humanos y juicios ejemplares que se llevaron a cabo contra miembros de las Fuerzas Armadas implicadas en la desaparición, tortura y represión durante la dictadura militar (1976-1983). El artículo examina un tema incómodo pero urgente ante los giros neoconservadores de la política latinoamericana: los sentidos que adquieren los testimonios para negar y eludir responsabilidades en crímenes de lesa humanidad.

Por último, Natalia de Marinis analiza en su artículo el testimonio experto en las disputas por la verdad en las Cortes de Inmigración en Estados Unidos, ante la solicitud de refugio de indígenas mexicanos. Analiza un aspecto del peritaje relacionado con la construcción de la huella testimonial del desplazamiento forzado y la guerra en México que se quiere silenciar en Estados Unidos ante la criminalización de migrantes indocumentados. De Marinis documenta las disputas por la verdad en las cortes y los dilemas que enfrenta el testimonio experto.

Nuestra pregunta por el testimonio abarca una preocupación académica y también política. Nos interesamos por sus usos y destinos desde una perspectiva académica, y por sus potencialidades y riesgos en contextos actuales de impunidad y retroceso en la garantía de derechos. Ubicamos sus posibilidades en arenas diversas, en apuestas colectivas de resistencia y en construcciones institucionales de justicia débilmente sostenidas. D 


\section{Bibliografía}

Abad Faciolince, Héctor, 2014, El olvido que seremos, Seix Barral, Bogotá.

Acedo Alonso, Noemí, 2017, "El género testimonio en Latinoamérica: aproximaciones críticas en busca de su definición, genealogía y taxonomía”, en Latinoamérica, núm. 64, pp. 39-69.

Alcoba, Laura, 2008, La casa de los conejos, Edhasa, Buenos Aires.

Benjamin, Walter, 2001, “El narrador”, en Walter Benjamin, Para una crítica de la violencia. I/uminaciones IV, Taurus, Madrid, pp. 111-134.

Beverley, John, 2008, "Testimonio, Subalternity, and Narrative Authority”, en Sara Castro-Klarén (ed.), A Companion to Latin American Literature and Culture, Blackwell, Oxford y Malden, pp. 571-583.

Burgos, Elizabeth, 1983, Me llamo Rigoberta Menchú y asi me nació la conciencia, Casa de las Américas, La Habana.

Calveiro, Pilar, 2006, “Testimonio y memoria en el relato histórico”, en Acta Poética, vol. 27, núm. 2, pp. 65-86.

Campbell, Howard, Jeremy Slack y Brian Diedrich, 2017, "Mexican Immigrants, Anthropology, and United States Law: Pragmatics, Dilemmas, and Ethics of Expert Witness Testimony”, en Human Organization, vol. 76, núm. 4, pp. 326-335.

Castillejo Cuéllar, Alejandro, 2007, "La globalización del testimonio: historia, silencio endémico y los usos de la palabra”, en Antípoda, núm. 4 , pp. 76-99.

—_, 2009, Los archivos del dolor: ensayos sobre la violencia y el recuerdo en la Sudáfrica contemporánea, Universidad de los Andes, Bogotá.

Colom, Yolanda, 1998, Mujeres en la alborada, guerrilla y participación femenina en Guatemala 1973-1978. Testimonio, Artemis \& Edinter, Guatemala.

Crosby, Alison y Brinton Lykes, 2011, "Mayan Women Survivors Speak: The Gendered Relations of Truth Telling in Postwar Guatemala”, en The International Journal of Transitional Justice, vol. 5, núm. 3, pp. 456-476.

Forné, Anna, 2014, "El género testimonial revisitado. El premio testimonio de Casa de las Américas (1970-2007)", en El Taco en la Brea, vol. 1, núm. 1, pp. 216-232.

Franco, Jean, 2002, "Si me permiten hablar: la lucha por el poder interpretativo", en John Beverley y Hugo Achugar (coords.), La voz de/ otro: testimonio, subalternidad y verdad narrativa, Universidad Rafael Landivar, Guatemala, pp. 121-128.

Friedman, Judith, 2008, Mi hijo Raúl Pellegrin. Comandante José Miguel, LOM, Santiago.

García Villegas, René, 1990, Soy testigo. Dictadura, tortura, injusticia, Amerinda, Santiago.

Givoni, Michal, 2011, “Witnessing/Testimony”, en Mafte’akh, núm. 2, pp. 147-169.

Gutiérrez, Carlos y Gervasio Noailles (comps.), 2014, Destinos del testimonio: víctima, autor, silencio. Los testigos en los juicios por crímenes de lesa humanidad, Letra Viva, Buenos Aires.

Halbwachs, Maurice, 2004 [1968], La memoria colectiva, Prensas Universitarias de Zaragoza, Zaragoza.

Hernández Castillo, Rosalva Aída y Héctor Ortiz Elizondo, 2012, “Asunto: violación de una indígena me’phaa por miembros del Ejército Mexicano. Presentado ante la Corte Interamericana de Derechos Humanos. Abril-mayo de 2010. Una historia de agravios y desagravios: el Ejército Mexicano ante la colDH", en Boletín del Colegio de Etnólogos y Antropólogos Sociales, año 2012, pp. 67-81.

Jelin, Elizabeth, 2002, Los trabajos de la memoria, Siglo XXI Editores, Buenos Aires.

Jimeno, Myriam, Daniel Varela y Ángeles Castillo, 2015, Después de la masacre, emociones y política en el Cauca indio, Universidad Nacional de Colombia/Instituto Colombiano de Antropología e Historia, Bogotá.

—_, 2018, "Violence, Emotional Communities and Political Action in Colombia", en Morna Macleod y Natalia de Marinis (eds.), Resisting Violence: Emotional Communities in Latin America, Palgrave Macmillan, Basingstoke, pp. 23-52.

Levi, Primo, 1989, Los hundidos y los salvados, El Aleph, Barcelona.

Lira, Elizabeth, 2007, “El testimonio de experiencias políticas traumáticas: terapia y denuncia en Chile (1973-1985)”, en Anne Pérotin-Dumon (dir.), Historizar el pasado vivo en América Latina, Universidad Alberto Hurtado, Santiago, pp. 1-40. Disponible en línea: <http://www. historizarelpasadovivo.cl/downloads/lira.pdf>.

Macleod, Morna y Natalia de Marinis (eds.), 2018, Resisting Violence: Emotional Communities in Latin America, Palgrave Macmillan, Basingstoke.

(coords.), 2019, Comunidades emocionales: resistiendo a las violencias en América Latina, Universidad Autónoma MetropolitanaXochimilco/Instituto Colombiano de Antropología e Historia, México y Bogotá. 
Pollak, Michael, 2006, Memoria, olvido, silencio: la producción social de identidades frente a situaciones límite, Al Margen, La Plata.

Poniatowska, Elena, 1971, La noche de Tlatelo/co, Era, México.

Rappaport, Joanne, 2000, La política de la memoria. Interpretación indigena de la historia en los Andes colombianos, Universidad del Cauca, Popayán.

Ricoeur, Paul, 1999, “La marca del pasado”, en Historia y Grafía, núm. 13, pp. 157-185.

Robledo Silvestre, Carolina, 2017, Drama social y política del duelo: las desapariciones de la guerra contra las drogas en Tijuana, El Colegio de México, México.

Rodríguez Maeso, Silvia, 2011, “Testimonios, discurso experto y comisiones de la verdad: el contexto de la denuncia”, en Política y Sociedad, vol. 48, núm. 3, pp. 587-602.

Sarlo, Beatriz, 2006, Tiempo pasado. Cultura de la memoria y giro subjetivo. Una discusión, Siglo XXI Editores, México.

Stephen, Lynn, 2016, Somos la cara de Oaxaca. Testimonios y movimientos sociales, Centro de Investigaciones y Estudios Superiores en Antropología Social, México.

, 2017, "Bearing Witness: Testimony in Latin American Anthropology and Related Fields", en The Journal of Latin American and Caribbean Anthropology, vol. 22, núm. 1, pp. 85-109.

Stern, Steve, 2000, "De la memoria suelta a la memoria emblemática: hacia el recordar y el olvidar como proceso histórico (Chile, 1973-1998)", en Mario Garcés (comp.), Memoria para un nuevo sig/o. Chile, miradas a la segunda mitad del sig/o xx, LOM/Eco Educación y Comunicaciones/Universidad de Santiago de Chile, Santiago, pp. 11-33.

Taylor, Diana, 2003, The Archive and the Repertoire: Performing Cultural Memory in the Americas, Duke University Press, Durham.

Theidon, Kimberly, 2009, "La teta asustada: una teoría sobre la violencia de la memoria", en /deele. Revista del Instituto de Defensa Legal, núm. 191, pp. 56-63.

Vecchioli, Virginia, 2012, "Derechos humanos y violencia política en la Argentina. Disputas en torno a la memoria del pasado reciente", en A Contracorriente, vol. 10, núm. 1, pp. 249-279.

Vela Castañeda, Manolo, 2014, Los pelotones de la muerte. La construcción de los perpetradores del genocidio guatemalteco, El Colegio de México, México.

Viezzer, Moema, 1977, "Si me permiten hablar...". Testimonio de Domitila, una mujer de las minas de Bolivia, Siglo XXI Editores, México. Wieviorka, Annette, 2006, The Era of The Witness, Cornell University Press, Ithaca.

Yúdice, George, 2002, "Testimonio y concientización”, en John Beverley y Hugo Achugar (coords.), La voz del otro: testimonio, subalternidad y verdad narrativa, Universidad Rafael Landívar, Guatemala, pp. 221-242. 